\title{
Early- and mid-term outcomes after transcatheter aortic valve implantation. Data from a single-center registry
}

\author{
Maciej Bagienski, Pawel Kleczynski, Artur Dziewierz, Lukasz Rzeszutko, Danuta Sorysz, Jaroslaw Trebacz, \\ Robert Sobczynski, Marek Tomala, Maciej Stapor, Andrzej Gackowski, Dariusz Dudek
}

Institute of Cardiology, Krakow, Poland

Adv Interv Cardiol 2016; 12, 2 (44): 122-127

DOI: 10.5114 /aic.2016.59362

\begin{abstract}
A bstract
Introduction: Transcatheter aortic valve implantation (TAVI) is a less invasive treatment option for elderly, high-risk patients with symptomatic severe aortic stenosis (AS) than aortic valve replacement. More importantly, TAVI improves survival and quality of life as compared to medical treatment in inoperable patients.

Aim: To assess early- and mid-term clinical outcomes after TAVI.

Material and methods: All consecutive high-risk patients with severe symptomatic AS undergoing TAVI from November 2008 to August 2014 were enrolled. The clinical and procedural characteristics, as well as clinical outcomes including mortality during 12-month follow-up, were assessed.

Results: A total of 101 consecutive patients underwent TAVI for native aortic valve stenosis (100\%). Patients were elderly, with a median age of 81.0 (76.0-84.0) years, 60.4\% were female and 83.2\% presented with NYHA III/IV. Median baseline EuroSCORE I and STS scores were 14.0 (10.0-22.5)\% and 12.0 (5.0-24.0)\%, respectively. The main periprocedural and in-hospital complications were minor vascular complications, bleeding requiring blood transfusions, and the need for a permanent pacemaker. In-hospital, 30-day, 6-month and 12-month mortality rates were 6.9\%, 10.9\%, 15.8\% and $17.8 \%$, respectively.

Conclusions: A mortality rate of $<20 \%$ after 12 months seems acceptable given the high-risk population enrolled.
\end{abstract}

Key words: aortic stenosis, high-risk patients, transcatheter aortic valve implantation, outcomes, registry.

\section{Introduction}

Aortic stenosis (AS) is the most common valvular heart disease in elderly patients and is associated with worse clinical outcomes [1]. Surgical aortic valve replacement (AVR) was for decades the standard treatment for patients with symptomatic, severe AS [2]. Transcatheter aortic valve implantation (TAVI) is a less invasive treatment option for elderly, high-risk patients with symptomatic severe AS than AVR. More importantly, TAVI improves survival [3] and quality of life [4] as compared to medical treatment in inoperable patients. Transcatheter aortic valve implantation is also non-inferior to AVR regarding survival in selected patients [5]. A successful TAVI procedure requires complex selection of patients, including detailed imaging information of the aortic valve anatomy and the peripheral arteries, and also critical clinical assessment by an interdisciplinary heart team [6]. The TAVI program started in 2008 in our institution, resulting in a single-center, prospective registry evaluating the safety and efficacy of consecutive TAVI procedures.

\section{Aim}

Thus, we sought to evaluate early- and mid-term clinical outcomes after TAVI in a single-center setting.

\section{Material and methods}

The study protocol was approved by the institutional Ethical Board. A total of 101 consecutive high-risk elderly patients with severe symptomatic AS undergoing TAVI were enrolled. Patient screening and selection was performed by a multidisciplinary heart team supported by clinical and imaging resources. TAVI procedures were performed using Edwards Sapien, Edwards Sapien XT, Edwards Sapien 3 (Edwards Lifesciences, Irvine, USA) Medtronic Corevalve (Medtronic Inc., Min-

\section{Corresponding author:}

Pawel Kleczynski MD, PhD, $2^{\text {nd }}$ Department of Cardiology and Cardiovascular Interventions, University Hospital, 17 Kopernika St, 31-501 Krakow, Poland, phone: +48 1242471 81, fax: +48 1242471 84, e-mail: kleczu@interia.pl

Received: 8.12.2015, accepted: 13.01.2016. 
neapolis, USA) and JenaValve (JenaValve Technology, Munich, Germany). Access routes were transfemoral and transapical. Procedures were performed under

Table I. Baseline characteristics $(n=101)$

\begin{tabular}{|c|c|}
\hline Variable & Result \\
\hline Age, median (IQR) [years] & $81.0(76.0-84.0)$ \\
\hline Age $\geq 80$ years, $n(\%)$ & $59(58.4)$ \\
\hline Female, $n(\%)$ & $61(60.4)$ \\
\hline Body mass index, median (IQR) $\left[\mathrm{kg} / \mathrm{m}^{2}\right]$ & $28.0(25.2-31.1)$ \\
\hline Arterial hypertension, $n(\%)$ & $94(93.1)$ \\
\hline Diabetes mellitus, $n$ (\%) & $35(34.7)$ \\
\hline Hyperlipidemia, $n$ (\%) & $101(100.0)$ \\
\hline Previous MI, $n(\%)$ & $31(30.7)$ \\
\hline Previous PCl, $n(\%)$ & $29(28.7)$ \\
\hline Previous pacemaker, $n$ (\%) & $11(10.9)$ \\
\hline Previous CABG, $n(\%)$ & $17(16.8)$ \\
\hline eGFR, median (IQR) [ml/min/1.73 $\left.\mathrm{m}^{2}\right]$ & $61.0(39.0-81.0)$ \\
\hline Atrial fibrillation, $n(\%)$ & $35(34.7)$ \\
\hline Previous stroke, $n(\%)$ & $10(9.9)$ \\
\hline Chronic obstructive pulmonary disease, $n(\%)$ & $12(11.9)$ \\
\hline \multicolumn{2}{|l|}{ Symptoms, $n(\%):$} \\
\hline \multicolumn{2}{|l|}{ Canadian Cardiovascular Society: } \\
\hline । & $12(11.7)$ \\
\hline$\|$ & $24(23.5)$ \\
\hline III + IV & $66(64.7)$ \\
\hline \multicolumn{2}{|l|}{ New York Heart Association: } \\
\hline । & $0(0.0)$ \\
\hline II & $17(16.8)$ \\
\hline III + IV & $84(83.2)$ \\
\hline \multicolumn{2}{|l|}{ Aortic valve parameters: } \\
\hline TG max, median (IQR) [mm Hg] & $87.0(71.5-108.0)$ \\
\hline TG mean, median (IQR) [mm Hg] & $51.0(42.5-66.5)$ \\
\hline Aortic valve area, median (IQR) $\left[\mathrm{cm}^{2}\right]$ & $0.6(0.4-0.8)$ \\
\hline LVEF, median (IQR) (\%) & $60.0(47.5-65.0)$ \\
\hline \multicolumn{2}{|l|}{ Risk of surgery: } \\
\hline Logistic EuroSCORE I, median (IQR) [\%] & $14.0(10.0-22.5)$ \\
\hline $\begin{array}{l}\text { Society of Thoracic Surgeons Score, median } \\
(\mathrm{IQR})[\%]\end{array}$ & $12.0(5.0-24.0)$ \\
\hline $\begin{array}{l}C A B G \text { - coronary artery bypass grafting, eGFR - estimated } \\
\text { rate, IQR - interquartile range, } L V E F-\text { left ventricle ejectio } \\
\text { cardial infarction, } P C I \text { - percutaneous coronary intervent } \\
\text { gradient. }\end{array}$ & $\begin{array}{l}\text { glomerular filtration } \\
\text { n fraction, } M I-\text { myo- } \\
\text { ion, } T G-\text { transaortic }\end{array}$ \\
\hline
\end{tabular}

general anesthesia or analgosedation [7]. Antiplatelet therapy consisted of acetylsalicylic acid life-long and clopidogrel for 1 month, if the prolonged therapy was not required due to previous percutaneous coronary intervention $(\mathrm{PCl})$. Anticoagulation was continued only if indicated. Baseline characteristics as well as procedural and outcome data were collected. Endpoints of the study included all-cause mortality at discharge, 30 days, 6 months and 12 months. Cardiovascular mortality, cerebrovascular events, myocardial infarction, bleeding complications, vascular or access site-related complications and acute kidney injury were also assessed. All endpoints were assessed according to the recommendations of the Valve Academic Research Consortium (VARC) $[8,9]$.

Table II. Procedural data $(n=101)$

\begin{tabular}{|c|c|}
\hline Variable & Result \\
\hline Procedure time, mean \pm SD [min] & $97 \pm 32$ \\
\hline Amount of contrast, mean $\pm \mathrm{SD}[\mathrm{ml}]$ & $62 \pm 34$ \\
\hline General anesthesia, $n$ (\%) & $92(91.1)$ \\
\hline \multicolumn{2}{|l|}{ Procedure location, $n(\%)$ : } \\
\hline Catheterization laboratory & $72(71.3)$ \\
\hline Hybrid room & $28(27.7)$ \\
\hline Operating room & $1(1.0)$ \\
\hline \multicolumn{2}{|l|}{ Access site, $n(\%)$ : } \\
\hline Femoral & $78(77.2)$ \\
\hline Transapical & $21(20.8)$ \\
\hline Direct aortic & $2(2.0)$ \\
\hline Balloon predilatation, $n(\%)$ & $100(100.0)$ \\
\hline \multicolumn{2}{|l|}{ Device implanted, $n(\%)$ : } \\
\hline Edwards Sapien & $50(49.5)$ \\
\hline Edwards Sapien XT & $24(23.7)$ \\
\hline Edwards Sapien 3 & $3(2.9)$ \\
\hline Medtronic CoreValve & $20(19.8)$ \\
\hline Jena Valve & $4(4.0)$ \\
\hline \multicolumn{2}{|l|}{ Aortic regurgitation after TAVI, $n(\%)$ : } \\
\hline None & $37(48.7)$ \\
\hline Grade 1 & $33(43.4)$ \\
\hline Grade 2 & $5(6.6)$ \\
\hline Grade 3 & $1(1.3)$ \\
\hline Valve migration, $n(\%)$ & $1(1.0)$ \\
\hline Valve in valve, $n(\%)$ & $0(0.0)$ \\
\hline
\end{tabular}

SD - standard deviation, TAVI - transcatheter aortic valve implantation. 


\section{Statistical analysis}

Continuous variables are presented as the median (interquartile range (IQR)) or mean value with standard deviation, where applicable. Categorical variables are expressed as numbers (percentages). The mortality rates during follow-up are presented using the Kaplan-Meier curve. Changes in categories of NYHA (New York Heart Association) and CCS (Canadian Cardiovascular Society) grade between baseline and follow-up were tested using the $\chi^{2}$ test.

Table III. In-hospital outcomes and discharge medications $(n=101)$

\begin{tabular}{|c|c|}
\hline Variable & Result \\
\hline Length of in-hospital stay, mean \pm SD [days] & $11.5 \pm 5.8$ \\
\hline Cardiac tamponade, $n(\%)$ & $4(4.0)$ \\
\hline New permanent pacemaker implantation, $n(\%)$ & $9(8.9)$ \\
\hline Any packed red blood cell infusion, $n(\%)$ & $26(25.7)$ \\
\hline $\begin{array}{l}\text { Number of packed red blood cell infusion units, } \\
\text { mean } \pm \text { SD }\end{array}$ & $3.0 \pm 1.6$ \\
\hline Acute kidney failure requiring dialysis, $n$ (\%) & $5(5.0)$ \\
\hline \multicolumn{2}{|l|}{ Medication at discharge, $n(\%)$ : } \\
\hline Acetylsalicylic acid + clopidogrel & $62(61.4)$ \\
\hline $\begin{array}{l}\text { Acetylsalicylic acid + clopidogrel + oral } \\
\text { anticoagulation }\end{array}$ & $33(32.7)$ \\
\hline
\end{tabular}

All tests were two-tailed, and a $p$ value $<0.05$ was considered statistically significant. All statistical analysis was performed using SPSS 15.0 (SPSS, Inc., Chicago, IL, USA).

\section{Results}

A total of 101 patients underwent an elective TAVI procedure between November 2008 and November 2014 for degenerative AS (100\%). All patients were scheduled by the heart team for TAVI. The median age was 81.0 (76.084.0) years, and $60.4 \%$ were female. All patients were symptomatic, $83.2 \%$ presenting with NYHA class III + IV. The median aortic valve area (AVA) was $0.7(0.5-0.8) \mathrm{cm}^{2}$ and the median value of maximal/mean transaortic gradient was 89.5 (59.0-119.0)/54.5 (34.0-74.0) mm Hg. All patients were considered high-risk according to logistic EuroSCORE I 16.5 (7.0-23.0)\% and STS (Society of Thoracic Surgeons) score 15.4 (4.0-24.0)\%. Baseline characteristics of the patients are presented in Table I. Procedural data and results are presented in Table II. The TAVI procedures were performed in the catheterization laboratory (71\%), hybrid room (27.7\%) and operating room (1.9\%) using either general anesthesia (91\%) or analgosedation (9\%). The transfemoral approach was the most commonly used (Table II). All patients underwent balloon aortic valvuloplasty prior to valve deployment. All patients received only one prosthesis, so no valve-in-valve procedure was necessary. Conversion to open heart surgery was required in $2(2.0 \%)$ cases. In-hospital course data are presented in Table III. A total of $30 \%$ of patients were discharged

Table IV. In-hospital, 30-day, 6-month and 12-month clinical outcomes

\begin{tabular}{|c|c|c|c|c|}
\hline Variable & Immediate (in-hospital) & 30 days & 6 months & 12 months \\
\hline \multicolumn{5}{|l|}{ Mortality, $n(\%):$} \\
\hline All-cause & $7(6.9)$ & $11(10.9)$ & $16(15.8)$ & $18(17.8)$ \\
\hline Cardiovascular & $7(6.9)$ & $11(10.9)$ & $16(15.8)$ & $18(17.8)$ \\
\hline "On the table" & $0(0)$ & & & \\
\hline Cerebrovascular incident, $n$ (\%) & $2(2.0)$ & $6(5.9)$ & $8(7.9)$ & $8(7.9)$ \\
\hline TIA, $n(\%)$ & $0(0)$ & $2(2.0)$ & $4(4.0)$ & $4(4.8)$ \\
\hline Minor stroke, $n(\%)$ & $0(0)$ & $1(1.0)$ & $1(1.0)$ & $1(1.0)$ \\
\hline Major stroke, $n(\%)$ & $2(2.0)$ & $3(3.0)$ & $3(3.0)$ & $3(3.0)$ \\
\hline Myocardial infarction, $n$ (\%) & $3(3.0)$ & $4(4.0)$ & $4(4.0)$ & $4(4.0)$ \\
\hline Acute kidney injury, $n$ (\%): & $70(69.3)$ & - & - & - \\
\hline Stage 1 & $46(45.5)$ & & & \\
\hline Stage 2 & $19(18.8)$ & & & \\
\hline Stage 3 & $5(5.0)$ & & & \\
\hline Bleeding, $n$ (\%): & $28(27.7)$ & - & - & - \\
\hline Minor, $n(\%)$ & $2(2.0)$ & & & \\
\hline Major, $n(\%)$ & $16(15.8)$ & & & \\
\hline Life-threatening, $n(\%)$ & $10(9.9)$ & & & \\
\hline Access site complication, $n$ (\%) & $8(7.9)$ & - & - & - \\
\hline New permanent pacemaker implantation, $n(\%)$ & $9(8.9)$ & $14(13.9)$ & $15(14.9)$ & $16(15.8)$ \\
\hline
\end{tabular}


A

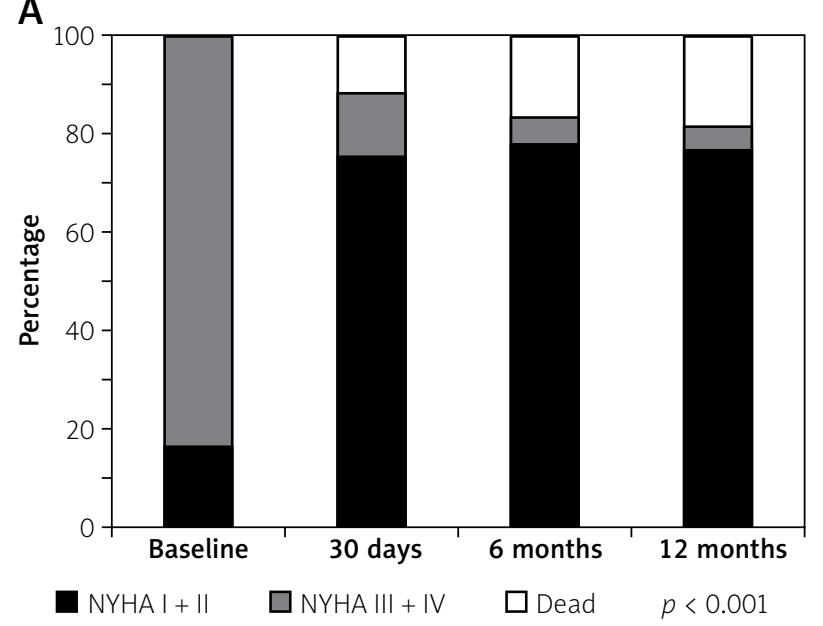

B

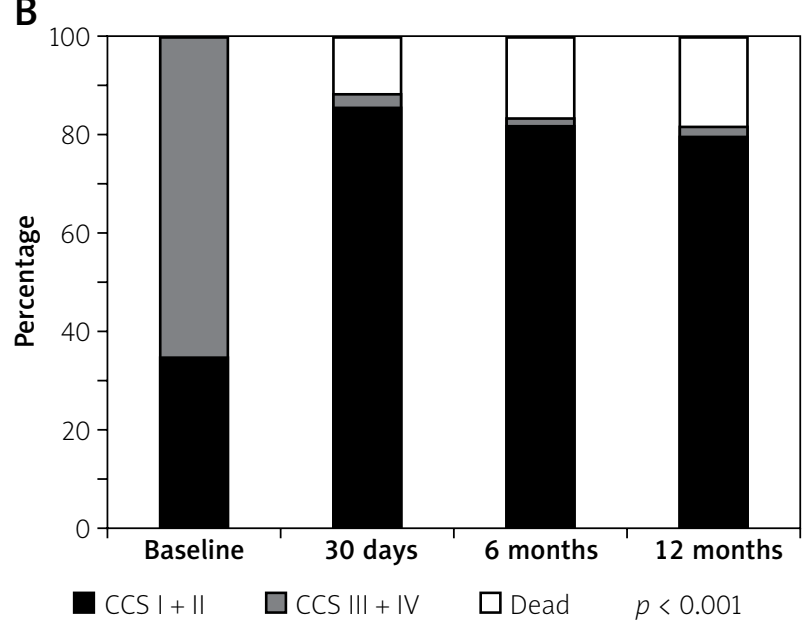

Figure 1. New York Heart Association class (A) and Canadian Cardiovascular Society class (B) status at follow-up

to a rehabilitation clinic, while $60.2 \%$ of patients were discharged home and $9.8 \%$ of patients were sent back to the referring hospital. Immediate (in-hospital) clinical outcomes are provided in Table IV.

Short-term clinical outcomes within the first 30 days after TAVI are presented in Table IV. Cumulative all-cause mortality was $10.9 \%$. All deaths were due to cardiovascular causes. The overall rate of cerebrovascular accidents after 30 days was $5.0 \%$. The TAVI was effective in symptomatic alleviation (Figure 1), showing a reduction of dyspnea from $83.2 \%$ of patients in NYHA class III + IV at baseline to $13.2 \%$ at 30 -day follow-up $(p<0.001)$ and CCS class III + IV in $64.7 \%$ of patients at baseline to $2.9 \%$ at 30 days $(p<0.001)$.

Midterm (6- and 12-month) clinical outcomes are presented in Table IV. Cumulative all-cause mortality for 6 and 12 months was $15.8 \%$ and $17.8 \%$, respectively. All deaths were due to cardiovascular causes. The TAVI was still effective in symptom alleviation (Figure 1), showing a reduction of dyspnea from $83.2 \%$ of patients in NYHA class III + IV at baseline to $5.6 \%$ at 6 months and $4.9 \%$ at the 12 -month follow-up $(p<0.001$, Figure $1 \mathrm{~A})$. CCS class III + IV was present only in $1.9 \%$ of patients after 6 and 12 months (both $p<0.001$, Figure 1 B). Figure 2 represents the all-cause mortality rate during 12 -month follow-up. Echocardiographic data at 30 days, 6 months

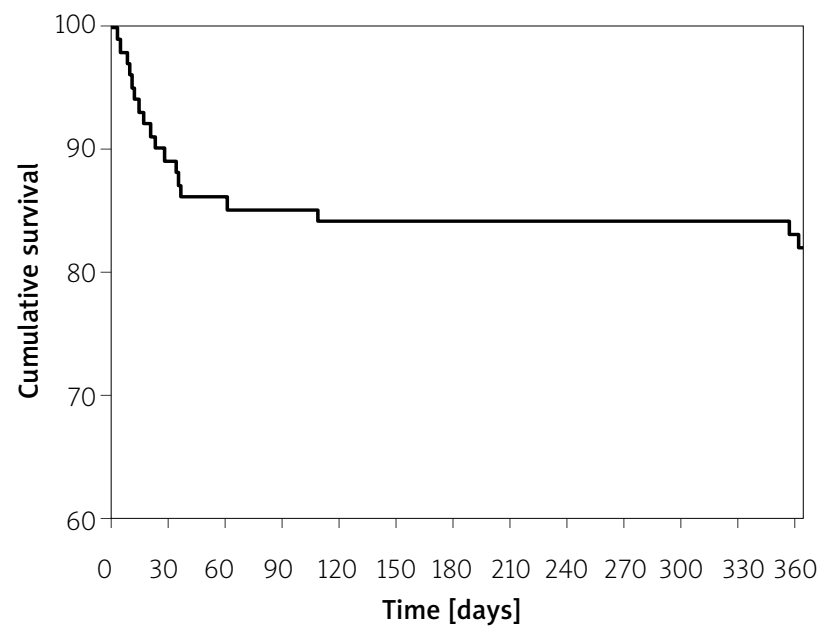

Figure 2. Incidence of all-cause mortality after transcatheter aortic valve implantation at 12-month follow-up

and 12 months are provided in Table V. Only 1 patient had a severe aortic regurgitation (AR) associated with paravalvular leak after Medtronic CoreValve implantation (Table IV). New pacemaker implantation was required in $16(15.8 \%)$ patients after 12 months due to third or high grade second degree atrioventricular block. The in-hospital rate of new pacemaker implantation was only $8.9 \%$.

Table V. Echocardiographic data at 30 days, 6 months and 12 months following transcatheter aortic valve implantation

\begin{tabular}{lccc} 
TG & 30 days & $\mathbf{6}$ months & 12 months \\
\hline TG max, mean \pm SD $[\mathrm{mm} \mathrm{Hg}]$ & $17.7 \pm 5.2$ & $19.2 \pm 8.5$ & $19.8 \pm 7.7$ \\
\hline TG mean, mean \pm SD $[\mathrm{mm} \mathrm{Hg}]$ & $9.7 \pm 3.1$ & $10.1 \pm 5.0$ & $10.4 \pm 3.9$ \\
\hline LVEF, mean \pm SD [\%] & $59.9 \pm 12.4$ & $62.0 \pm 10.1$ & $62.6 \pm 9.4$
\end{tabular}

LVEF-left ventricle ejection fraction, TG - transaortic gradient. 


\section{Discussion}

The study provides data on clinical outcomes of in-hospital, 30-day, 6- and 12-month follow-up after TAVI in our center. In our study, the all-cause mortality rate at 30 days remains below the estimated risk by logistic EuroSCORE I and STS score (10.9\% vs. $14 \%$ and $12 \%$, respectively), which is comparable to data published by other European TAVI centers [10-15]. This may be due to careful patient selection by the multidisciplinary Heart Team also in terms of the particular device and access site. All deaths within the first 30 days and 6 and 12 months following TAVI were due to cardiovascular causes. The incidence of in-hospital cerebrovascular incidents was comparable to rates reported in other registries. In Germany, periprocedural stroke after TAVI was reported in $1.7 \%$ to $2.3 \%$ [15], whereas the stroke rates in the French registry were $3.4 \%$ [11], and $4.1 \%$ in the UK [14]. A 30-day rate of $4.9 \%$ of cerebrovascular incidents is relatively high but still comparable with other data. Technological improvement, more standardized procedural techniques and cerebral protection during the procedure may help in reducing these disabling adverse events. However, recent studies evaluating cerebral protection devices have not shown any benefit [16]. The incidence of cerebrovascular events at 6 and 12 months was $7 \%$, probably due to new onset of atrial fibrillation. The bleeding rate in the periprocedural period was relatively high, reaching $27.7 \%$, with the need of red blood cell infusion in $25.7 \%$ of patients. This event rate is higher than previously published [10-15], and we thought it might have been a result of the operator's learning curve and only associated with in-hospital course. However, we performed an additional data review and found that the majority of bleeding complications were associated with gastrointestinal tract bleeding, probably linked to anticoagulation/antiplatelet therapy. Bleeding complications and red blood cell transfusion may be linked with impaired outcome after TAVI [17]. Acute kidney injury was quite frequent in our cohort of patients after TAVI (69\%); however, more than $60 \%$ of them had chronic renal failure at baseline. Dialysis was required in only $5 \%$ of subjects. Evidence on the safety and efficacy of TAVI in patients with acute kidney injury is incoherent. Data by Gargiulo et al. showed that postoperative acute kidney injury significantly increased early and 1-year all-cause and cardiovascular mortality, but also early myocardial infarction, life-threatening bleeding, need for transfusion, and dialysis [18]. However, in a study by Goebel et al., preoperative chronic kidney disease did not increase the risk of mortality and acute kidney injury after TAVI [19]. Paravalvular leak (PVL) also remains a significant complication associated with TAVI, which may cause higher mortality rates in a long-term follow-up [2]; however, there are some data suggesting no influence on the mid-term outcomes [20]. In our subset of patients, PVL was not a significant clinical issue. Pacemaker implantation following TAVI occurred in $15.8 \%$ of patients within 12 months, which is concordant with other data [21-25]. The in-hospital pacemaker implantation rate was $8.9 \%$, so there is a constant need for performing scheduled follow-up visits for TAVI patients to diagnose and treat new conduction disturbances.

Our study had a relatively small sample size, which is a consequence of the limited reimbursement for TAVI in Poland overall. The results are influenced by operators' learning curve for TAVI procedures. The completeness of follow-up is about $98 \%$, and thus we cannot exclude underreporting of events.

\section{Conclusions}

The TAVI is a favorable treatment option for elderly patients with severe AS who are at a high risk for surgery. A mortality rate of $<20 \%$ after 12 months seems acceptable given the high-risk population enrolled.

\section{Conflict of interest}

The authors declare no conflict of interest.

\section{References}

1. Ross J Jr, Braunwald E. Aortic stenosis. Circulation 1968; 38: 61-7. 2. Vahanian A, Alfieri O, Andreotti F, et al. Joint Task Force on the Management of Valvular Heart Disease of the European Society of Cardiology (ESC); European Association for Cardio-Thoracic Surgery (EACTS). Guidelines on the management of valvular heart disease (version 2012). Eur Heart J 2012; 33: 2451-96.

3. Leon MB, Smith CR, Mack M, et al. Transcatheter aortic-valve implantation for aortic stenosis in patients who cannot undergo surgery. N Engl J Med 2010; 363: 1597-607.

4. Kleczyński P, Bagieński M, Sorysz D, et al. Short- and intermediate-term improvement of patient quality of life after transcatheter aortic valve implantation: a single-center study. Kardiol Pol 2014; 72: 612-16.

5. Smith CR, Leon MB, Mack MJ, et al. Transcatheter versus surgical aortic-valve replacement in high-risk patients. N Engl J Med 2011; 364: 2187-98.

6. Vahanian A, Alfieri O. Guidelines on valvular heart disease in clinical practice. Eurolntervention 2013; 9: S11-3.

7. Kleczyński P, Sorysz D, Rzeszutko $t$, et al. Current approach to transfemoral aortic valve replacement. Kardiol Pol 2013; 71: 203-4.

8. Leon MB, Piazza N, Nikolsky E, et al. Standardized endpoint definitions for transcatheter aortic valve implantation clinical trials: a consensus report from the Valve Academic Research Consortium. Eur Heart J 2011; 32: 205-17.

9. Kappetein AP, Head SJ, Généreux P, et al. Valve Academic Research Consortium-2. Updated standardized endpoint definitions for transcatheter aortic valve implantation: the Valve Academic Research Consortium-2 consensus document. Eurointervention 2012; 8: 782-95.

10. Bosmans JM, Kefer J, De Bruyne B, et al. Belgian TAVI Registry Participants. Procedural, 30-day and one year outcome following CoreValve or Edwards transcatheter aortic valve implanta- 
tion: results of the Belgian national registry. Interact Cardiovasc Thorac Surg 2011; 12: 762-7.

11. Gilard $M$, Eltchaninoff $H$, lung $B$, et al. Registry of transcatheter aortic-valve implantation in high-risk patients. N Engl J Med 2012; 366: 1705-15.

12. Linke A, Gerckens U, Wenaweser P, et al. Treatment of high risk aortic stenosis patients with transcatheter Medtronic CoreValve Implantation: results from the International Multi-Center $\mathrm{Ad}$ vance Study. J Am Coll Cardiol 2012; 59: E8-8.

13. Moat NE, Ludman P, de Belder MA, et al. Long-term outcomes after transcatheter aortic valve implantation in high-risk patients with severe aortic stenosis: the U.K. TAVI (United Kingdom Transcatheter Aortic Valve Implantation) Registry. J Am Coll Cardiol 2011; 58: 2130-8.

14. Thomas M, Schymik G, Walther T, et al. Thirty-day results of the SAPIEN aortic Bioprosthesis European Outcome (SOURCE) Registry: a European registry of transcatheter aortic valve implantation using the Edwards SAPIEN valve. Circulation 2010; 122: 62-9.

15. Hamm CW, Mollmann H, Holzhey D, et al. The German Aortic Valve Registry (GARY): in-hospital outcome. Eur Heart J 2014; 35: 1588-98.

16. Praz F, Nietlispach F. Cerebral protection devices for transcatheter aortic valve implantation: is better the enemy of good? Eurointervention 2013; 9: S124-8.

17. Seiffert M, Conradi L, Terstesse AC, et al. Blood transfusion is associated with impaired outcome after transcatheter aortic valve implantation. Catheter Cardiovasc Interv 2015; 85: 460-7.

18. Gargiulo G, Sannino A, Capodanno D, et al. Impact of postoperative acute kidney injury on clinical outcomes after transcatheter aortic valve implantation: a meta-analysis of 5,971 patients. Catheter Cardiovasc Interv 2015; 86: 518-27.

19. Goebel N, Baumbach H, Ahad S, et al. Transcatheter aortic valve replacement: does kidney function affect outcome? Ann Thorac Surg 2013; 96: 507-12.

20. Kleczyński P, Zasada W, Bagieński M, et al. Paravalvular leak after TAVI: short-term results. Data from Polish national POL-TAVI registry. Cardiol J 2015 Oct 27 [Epub ahead of print]; doi: 10.5603/CJ.a2015.0071.

21. Bjerre Thygesen J, Loh PH, Cholteesupachai J, et al. Reevaluation of the indications for permanent pacemaker implantation after transcatheter aortic valve implantation. J Invasive Cardiol 2014; 26: 94-9.

22. Dizon JM, Nazif TM, Hess PL, et al. Chronic pacing and adverse outcomes after transcatheter aortic valve implantation. Heart 2015; 101: 1665-71.

23. Mouillet G, Lellouche N, Yamamoto M, et al. Outcomes following pacemaker implantation after transcatheter aortic valve implantation with CoreValve( $\left.{ }^{\circledR}\right)$ devices: results from the FRANCE 2 Registry. Catheter Cardiovasc Interv 2015; 86: E158-66.

24. Kochman J, Kołtowski L, Huczek Z, et al. Direct transcatheter aortic valve implantation - one-year outcome of a case control study. Postep Kardiol Inter 2014; 10: 250-7.

25. Sarı C, Baştuğ S, Ayhan H, et al. Transfemoral aortic valve implantation in severe aortic stenosis patients with prior mitral valve prosthesis. Postep Kardiol Inter 2015; 11: 304-11. 